Article

\title{
Incorporation of Hyperbranched Supramolecules into Nafion Ionic Domains via Impregnation and In-Situ Photopolymerization
}

Nadzrinahamin A. Nazir ${ }^{1}$, Thein Kyu ${ }^{1, *}$, Anna M. Reinsel ${ }^{2}$, Matthew Espe ${ }^{2}$, Mami Nosaka ${ }^{3}$, Hiruto Kudo $^{3}$ and Tadatomi Nishikubo ${ }^{3}$

1 Department of Polymer Engineering, University of Akron, Akron, OH 44325, USA; E-Mail: na10@zips.uakron.edu (N.A.N.)

2 Department of Chemistry, University of Akron, Akron, OH 44325, USA; E-Mails: amp53@zips.uakron.edu (A.M.R.); espe@uakron.edu (M.E.)

3 Department of Applied Chemistry, Kanagawa University, Rokkakubashi, Kanagawa-ku, Yokohama 221-8686, Japan; E-Mails: ma-nousaka177@taiyoink.co.jp (M.N.); kudouh06@kanagawa-u.ac.jp (H.K.);nishikubot@kanagawa-u.ac.jp (T.N.)

* Author to whom correspondence should be addressed; E-Mail: tkyu@uakron.edu.

Received: 1 October 2011; in revised form: 1 November 2011 / Accepted: 18 November 2011 / Published: 28 November 2011

\begin{abstract}
Nafion membranes were impregnated with photocurable supramolecules, viz., hyperbranched polyester having pendant functional carboxylic acid groups (HBPEAc-COOH) by swelling in methanol and subsequently photocured in-situ after drying. Structure-property relationships of the HBPEAc-COOH impregnated Nafion membranes were analyzed on the basis of Fourier transform infrared (FTIR) spectroscopy, solid-state nuclear magnetic resonance (SSNMR) and dynamic mechanical analysis (DMA). FTIR and SSNMR investigations revealed that about $7 \mathrm{wt} \%$ of $\mathrm{HBPEAc-COOH}$ was actually incorporated into the ionic domains of Nafion. The FTIR study suggests possible complexation via inter-species hydrogen bonding between the carboxylic groups of $\mathrm{HBPEAc-COOH}$ and the sulfonate groups of Nafion. The $\alpha$-relaxation peak corresponding to the glass transition temperature of the ionic domains of the neat Nafion-acid form was found to increase from $\sim 100$ to $\sim 130{ }^{\circ} \mathrm{C}$ upon impregnation with enhanced modulus afforded by the cured polyester network within the ionic domains. The AC impedance fuel cell measurement of the impregnated membrane exhibited an increasing trend of proton conductivity with increasing temperature, which eventually surpassed that of neat Nafion above $100{ }^{\circ} \mathrm{C}$. Of
\end{abstract}


particular importance is that the present paper is the first to successfully incorporate polymer molecules/networks into the Nafion ionic domains by means of impregnation with hyperbranched supramolecules followed by in-situ photopolymerization.

Keywords: Nafion; hyperbranched polyester; impregnation; proton conductivity

\section{Introduction}

With the emergence of proton fuel cells for clean energy, perfluorinated ionomer membrane, commercially known as Nafion, has received widespread attention from researchers in both academia and industry. By virtue of its outstanding proton conductivity [1,2], Nafion is currently regarded as the benchmarked polymer electrolyte membrane (PEM). One major drawback is that its operation temperature is limited to $70-80{ }^{\circ} \mathrm{C}$, above which the proton conduction progressively gets worse. In the actual proton fuel cell operation, a numbers of PEM fuel cells have to be staked to obtain desirable power output [3]. An evitable consequence is that the cell temperature rises significantly beyond the optimum operating temperature of Nafion. Hence, there is a growing interest for developing new PEM materials capable of functioning at high temperatures under the actual proton fuel cell operations.

There are several attempts to remedy the aforementioned shortcomings of Nafion perfluorinated ionomer membranes, especially to increase proton conduction at elevated temperatures [4,5]. One notable approach is the in-situ impregnation (or doping) by means of incorporating functional small molecules such as ionic liquids within the Nafion ionic domains/clusters [6-9]. Infusion of ionic liquids into Nafion has afforded considerable improvement in ionic conduction. In addition, the occurrence of specific interaction has been identified, i.e., hydrogen and/or ionic bonding between these small molecules and the sulfonate groups of Nafion has helped retaining these functional small molecules during use [8,9].

The main idea of the present research is to incorporate functional photopolymerizable supramolecules into the ionic domains and subsequently polymerize it in-situ to form functional polymer networks in order to prevent any potential leaching in actual fuel cell operations. Another goal is to improve proton conduction at elevated temperatures where Nafion performance has declined considerably.

In this manuscript, we have incorporated solid supramolecules such as photocurable hyperbranched (HB) polyester terminated with functional carboxylic acid groups, namely HBPEAc-COOH [10], into the micro-phase separated ionic domains of Nafion via swelling in methanol. It can be anticipated that the terminal carboxylic acid of HB will not only enhance ion exchange capacity, but also impart inter-species hydrogen bonding with the sulfonate groups of Nafion that provides paths for proton conduction. Subsequently, photo-crosslinking was performed in-situ to retain the modifier supramolecules within the ionic domains and also to enhance its proton conduction above the current operating temperature of Nafion in the reduced water environment. Suppression of the excessive swelling upon hydration is also expected through occupying available space within the ionic domains of Nafion by these supramolecules. The incorporated amount of HB supramolecules was evaluated by means of Fourier transform infrared (FTIR). The physical and structural characterization of the HB impregnated Nafion was performed using solid-state nuclear magnetic resonance (SSNMR), differential scanning 
calorimetry (DSC), thermogravimetric analysis (TGA), dynamic mechanical analysis (DMA), and AC impedance measurements under the proton fuel cell environment. Of particular importance is that the present work will be the first to successfully incorporate large polymer molecules into the ionic domains of Nafion through impregnation and subsequent in-situ polymerization of photopolymerizable hyperbranched polyester [10]. More importantly, the present approach will afford better dimensional and thermal stability of the impregnated membrane with improved proton conduction during high temperature proton fuel cell operations relative to the unmodified Nafion.

\section{Results and Discussion}

Prior to incorporation into the Nafion membranes, the physical and chemical characterization of HB polyester was conducted by means of DSC, FTIR and SSNMR. Figure 1 shows the DSC thermograms of pure HB polyesters before and after photocrosslinking. The movement of the glass transition $\left(\mathrm{T}_{\mathrm{g}}\right)$, i.e., the mid-point of the transition of pure $\mathrm{HB}$ from 79 to $95{ }^{\circ} \mathrm{C}$ after photocuring indicates that the overall motion of the HB polyester chains becomes restricted. The act of photocuring leads to the formation of a chemically crosslinked network structure with restricted chain motions.

Figure 1. Differential scanning calorimetry (DSC) thermograms of pure HBPEAc-COOH (a) before and (b) after photocuring exhibiting an increase in $\mathrm{T}_{\mathrm{g}}$ of the HBPEAc-COOH supramolecules upon photocuring.

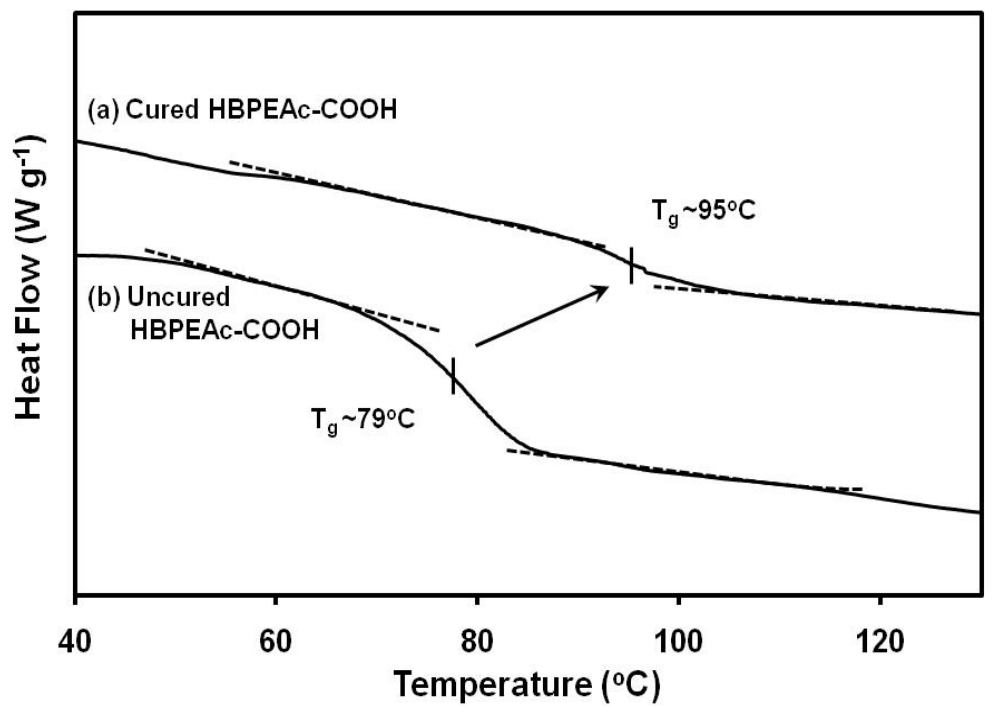

The overlay FTIR spectra of neat HBPEAc-COOH, HBPEAc-COOH with the initiator before photocuring and HBPEAc-COOH after photocuring are shown in Figure 2. Note that the amount of Irgacure 907 added was $3 \mathrm{wt} \%$ relative to the weight of $\mathrm{HBPEAc-COOH}$. It is evident that with the addition of photoinitiator to the neat $\mathrm{HB}$ polyester, there is no discernible change in the characteristic FTIR peaks such as $1,727 \mathrm{~cm}^{-1}(\mathrm{C}=\mathrm{O}$ carbonyl stretching $)$ and $/$ or $1,508 \mathrm{~cm}^{-1}(\mathrm{C}=\mathrm{C}$ stretching of the aromatic rings). A similar peak invariance can also be noticed in other characteristics bands at $1,230 \mathrm{~cm}^{-1}$ and $1,190 \mathrm{~cm}^{-1}$ corresponding to the $\mathrm{C}-\mathrm{O}-\mathrm{C}$ stretching of cyclic ether linkages of $\mathrm{HBPEAc}-\mathrm{COOH}$, and $830 \mathrm{~cm}^{-1}$ and $740 \mathrm{~cm}^{-1}$ peaks attributable to $\mathrm{C}-\mathrm{H}$ bending and $\mathrm{C}=\mathrm{C}$ aromatic out-of-plane bending vibrations. However, the addition of $3 \mathrm{wt} \%$ of photoinitiator is sufficient to 
achieve a high conversion (i.e., $\sim 60 \%$ ) in 4 min as demonstrated in an earlier paper [10]. Upon photocuring, the $\mathrm{C}=\mathrm{C}$ stretching band of acrylate near $1,630 \mathrm{~cm}^{-1}$ decreases as it transformed to a $\mathrm{C}-\mathrm{C}$ single bond after being attacked by free radicals of the photoinitiator. It should be emphasized that the HB polyester film is brittle without photocuring.

Figure 2. Fourier transform infrared (FTIR) spectra of (a) pure HBPEAc-COOH without initiator; (b) pure $\mathrm{HBPEAc-COOH}$ with initiator before curing; and (c) pure $\mathrm{HBPEAc-COOH}$ after photocuring demonstrating the reduction of acrylate $\mathrm{C}=\mathrm{C}$ stretching peak at $1,630 \mathrm{~cm}^{-1}$.

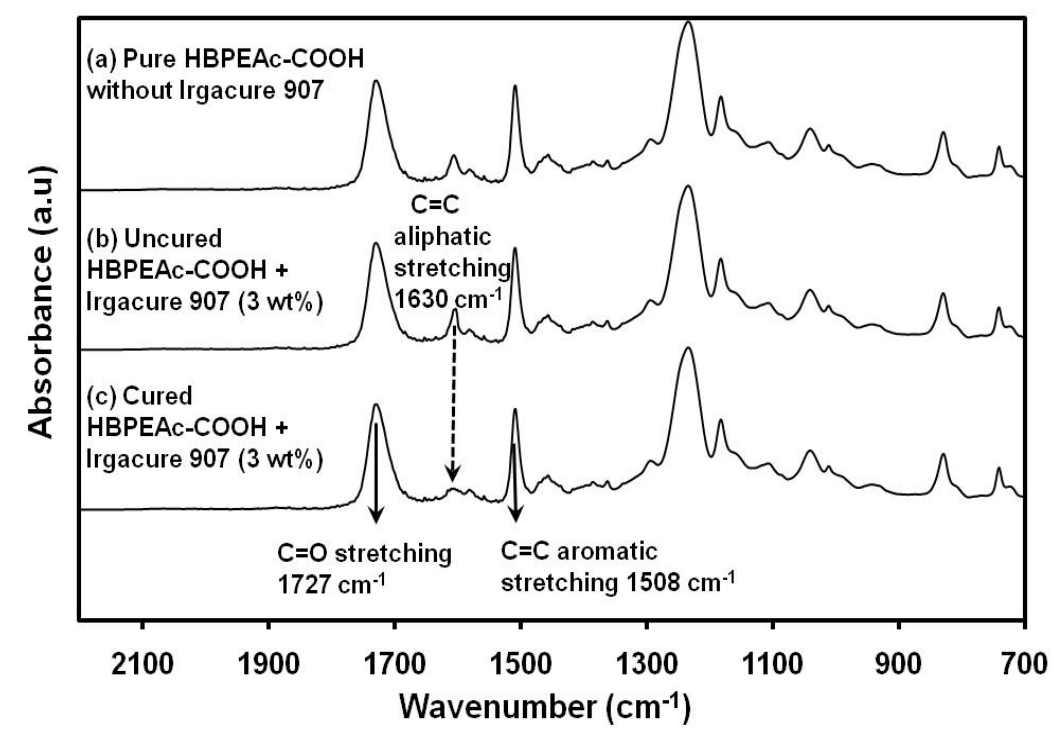

Figure 3. $125.6 \mathrm{MHz}{ }^{1} \mathrm{H}^{13} \mathrm{C} \mathrm{CP} / \mathrm{MAS}$ solid-state nuclear magnetic resonance (SSNMR) spectra of (a) HBPEAc-COOH impregnated Nafion and (b) cured neat HBPEAc-COOH. The spectra were collected using ${ }^{1} \mathrm{H}$ decoupling so that the peaks in the ${ }^{13} \mathrm{C}$ NMR spectrum only arise from the HBPEAc-COOH and photoinitiator (Irgacure 907). Peaks in (b) labeled with asterisk symbol (*) indicate the presence of the photoinitiator in the cured HB.

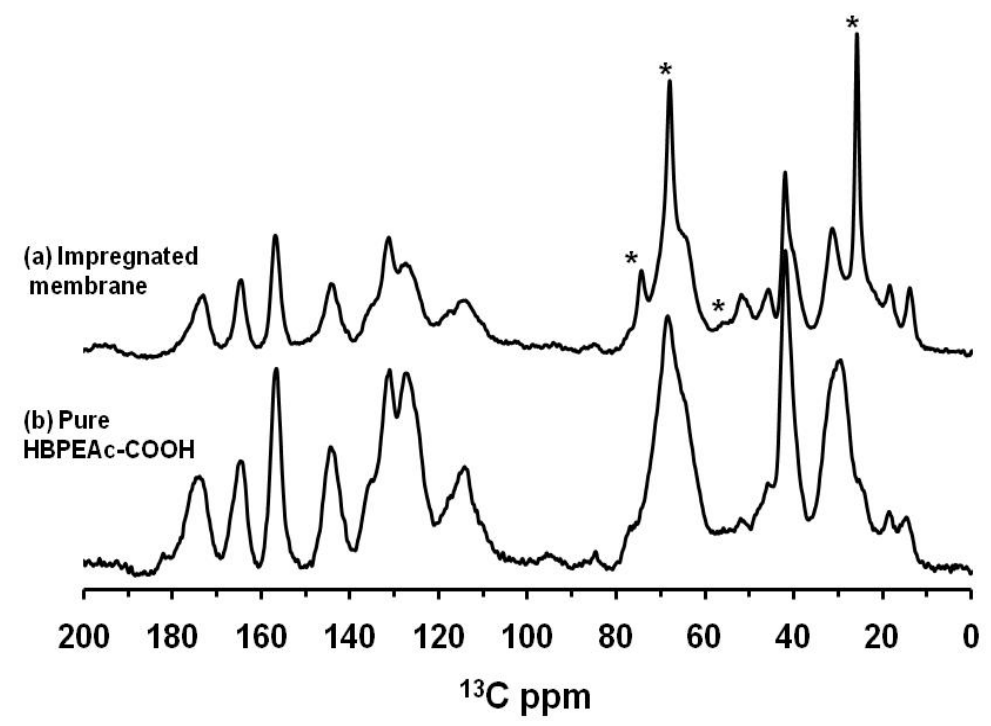

The ${ }^{13} \mathrm{C}$ CP/MAS NMR spectra acquired from cured HBPEAc-COOH and impregnated membranes are shown in Figure 3. It should be emphasized that the peaks in these spectra arise solely from the 
perprotio species of HBPEAc-COOH and photoinitiator. The spectra are complex as a result of the presence of many different types of carbons in the HB polyester. The most significant differences between the spectra from neat HBPEAc- $\mathrm{COOH}$ and impregnated membranes are the additional peaks at 26, 52, 68 and 74 ppm that arise from the substituted morpholino portion of the photoinitiator used to crosslink the HB supramolecule.

In order to quantify the amount of hyperbranched polyester incorporated, the total signal intensity of the ${ }^{13} \mathrm{C} \mathrm{CP} / \mathrm{MAS}$ NMR spectra of HBPEAc-COOH was evaluated. Correcting for the total number of transients collected and sample size, the amount of HBPEAc-COOH present in the impregnated membrane was determined to be $7 \pm 1 \mathrm{wt} \%$. As will be discussed later, this mass of HB polymer in the Nafion film matches the results obtained in the FTIR studies (vide infra).

The fluoropolymer backbone of the Nafion membrane was investigated to determine if there were any changes in this environment upon impregnating Nafion with $\mathrm{HBPEAc-COOH}$. The ${ }^{13} \mathrm{C} \mathrm{NMR}$ spectrum was collected using ${ }^{19} \mathrm{~F}-{ }^{13} \mathrm{C} \mathrm{CP}$ and ${ }^{19} \mathrm{~F}$ decoupling so that the peaks in the ${ }^{13} \mathrm{C}$ NMR spectrum unambiguously arise from the fluorocarbon component of Nafion. The ${ }^{13} \mathrm{C}$ spectrum from Nafion, Figure 4, is consistent with those reported previously [12-14] with the peaks at $114 \mathrm{ppm}$ from backbone $-\mathrm{CF}_{2}$ groups, $120 \mathrm{ppm}$ from the $-\mathrm{OCF}_{2}$ group, $122 \mathrm{ppm}$ from the $-\mathrm{CF}_{3}, 112 \mathrm{ppm}$ from the backbone $-\mathrm{CF}$ groups and $106 \mathrm{ppm}$ from the $-\mathrm{CF}$ side chain groups. There are no noticeable changes in the chemical shifts in the ${ }^{13} \mathrm{C}$ NMR spectra observed for the neat Nafion and impregnated membrane. These results suggest that there is little or no reactivity between the Nafion fluorocarbon backbone and HBPEAc-COOH. However, there is a slight change in linewidths, with the impregnated membrane having narrower lines than those of the neat Nafion. This minor change presumably occurs due to changes in the environment of the fluoro component as this portion of the membrane becoming more mobile. As will be discussed later, the SSNMR observations conform to the mechanical $\beta$-relaxation temperature observation which is attributable to the glass transition temperature of fluorocarbon backbone of pure Nafion. It appears that the inclusion of HB polyester in the Nafion ionic domains not only alters the environment of the ionic region, but also exerts some influence on the motion of the fluorocarbon backbone chain and/or side groups.

Figure 4. 125.6 MHz ${ }^{19} \mathrm{~F}^{13} \mathrm{C} \mathrm{CP} / \mathrm{MAS}$ SSNMR spectra of (a) impregnated membrane and (b) neat Nafion.

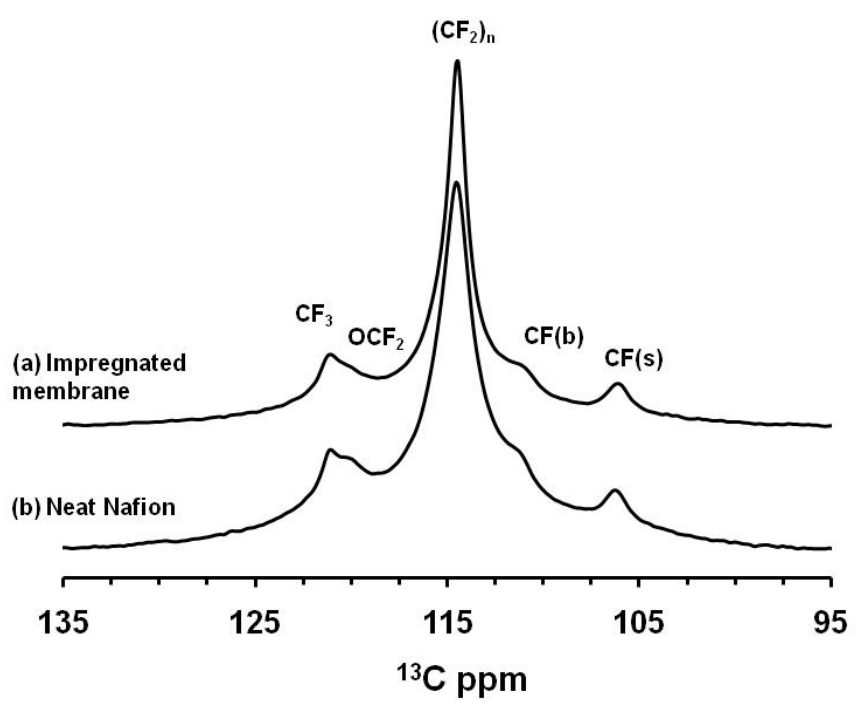


Nafion membranes were characterized prior to and after the infusion of the HB polyester by determining water content, HB polyester uptake levels, and the interactions between the Nafion and HB polyester. The ${ }^{1} \mathrm{H}$ NMR spectra of neat Nafion (Figure 5) shows a single peak at $8.6 \mathrm{ppm}$, and this chemical shift corresponds to approximately 2 water molecules per $\mathrm{SO}_{3} \mathrm{H}$ group present in the Nafion membrane $[15,16]$. The narrow linewidth of the peak indicates that the $\mathrm{H}_{2} \mathrm{O}$ molecules are mobile. The two broad peaks in the ${ }^{1} \mathrm{H}$ NMR spectrum from neat hyperbranched polyester, without the presence of initiator, are assigned to the aromatic protons, i.e., the downfield peak and the aliphatic protons, i.e., the upfield peak (Figure 5). After addition of the HB polymer to the Nafion membrane, the ${ }^{1} \mathrm{H}$ NMR spectra are similar, showing two broad peaks arising from the HB polyester. The presence of the additional peak in the aliphatic region of the spectrum of the impregnated membrane is attributed to the photoinitiator. The absence of any narrow peaks in the ${ }^{1} \mathrm{H}$ NMR spectrum from the impregnated membrane implies that there are no mobile water molecules present. This suggests that the infused HB supramolecules into the ionic regions of the Nafion presumably have replaced, if not all, some water molecules and also restricted the mobility of any remaining water molecules.

Figure 5. 499.5 MHz ${ }^{1} \mathrm{H}$ DP/MAS SSNMR spectra of (a) impregnated membrane; (b) pure HBPEAc-COOH; and (c) pure Nafion. The single narrow line at the chemical shift of $8.6 \mathrm{ppm}$ in (c) indicates the presence of approximately $2 \mathrm{H}_{2} \mathrm{O}$ molecules per $\mathrm{SO}_{3} \mathrm{H}$ site. The peak in (a) labeled with * is due to the photoinitiator.

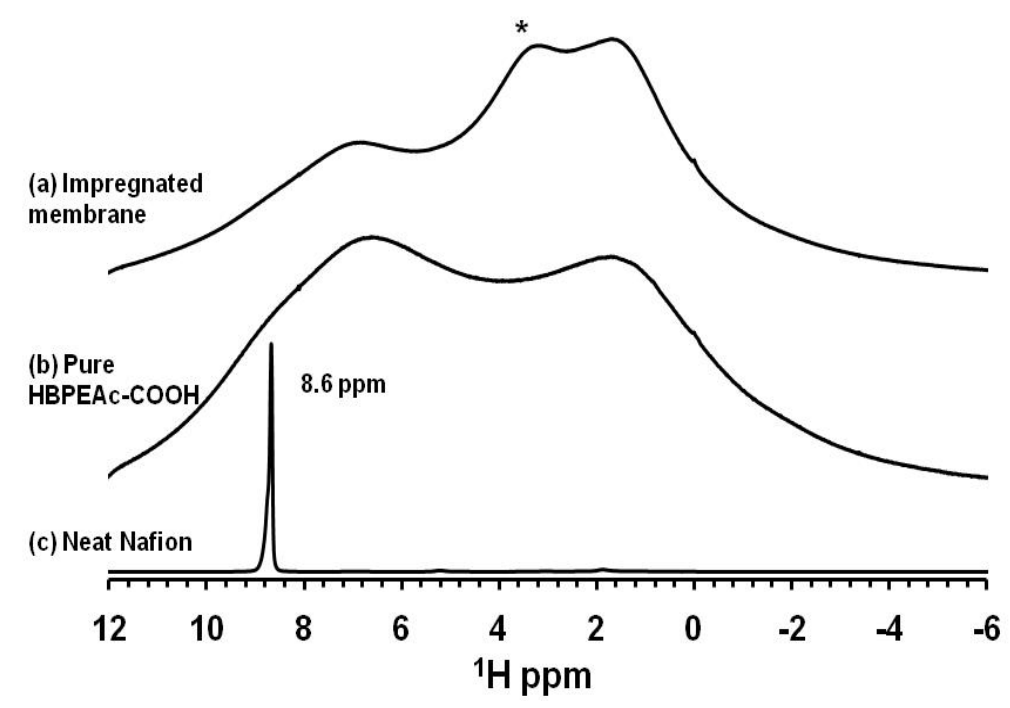

ATR-FTIR experiments were conducted in order to probe the interactions between HBPEAc-COOH and the ionic domains of Nafion, as well as to determine the estimated amounts of HBPEAc-COOH incorporated into Nafion. The FTIR spectra of neat Nafion, neat HBPEAc-COOH and impregnated membranes with different HB polyester feed ratios are depicted in Figure 6. These spectra were collected under the minimal moisture absorption at $100{ }^{\circ} \mathrm{C}$, e.g., bound water. At a higher FTIR wavenumber range around 3,300-3,600 $\mathrm{cm}^{-1}$, the IR absorption band is extremely broad so much so that the peak position is not identifiable. This broad band implies the presence of bound water within pure Nafion. On the other hand, the cured HBPEAc-COOH exhibits a pronounced $\mathrm{O}-\mathrm{H}$ stretching band (at $\sim 3,500 \mathrm{~cm}^{-1}$ ) albeit broad, arising from its pendant carboxylic acid functionalities [17] which 
may be interacting with some bound water molecules. With impregnation of HB supramolecules into Nafion, the broad $\mathrm{O}-\mathrm{H}$ stretching band remains virtually stationary with increasing $\mathrm{HB}$ contents from $2-10 \mathrm{wt} \%$ [see Figure 6(a)].

Figure 6. (a) FTIR spectra of the broad $\mathrm{O}-\mathrm{H}$ stretching band of impregnated membrane showing a slight movement to lower wavenumber as the HB amount increases; (b) the S-O stretching band of impregnated membranes showing a systematic shift of the $\mathrm{S}-\mathrm{O}$ band to a lower wavenumber (i.e., about $9 \mathrm{~cm}^{-1}$ ) with increasing amount of HBPEAc-COOH suggesting inter-species hydrogen bonding interaction between the carboxylic acid of HBPEAc-COOH and the sulfonic acid group of Nafion.
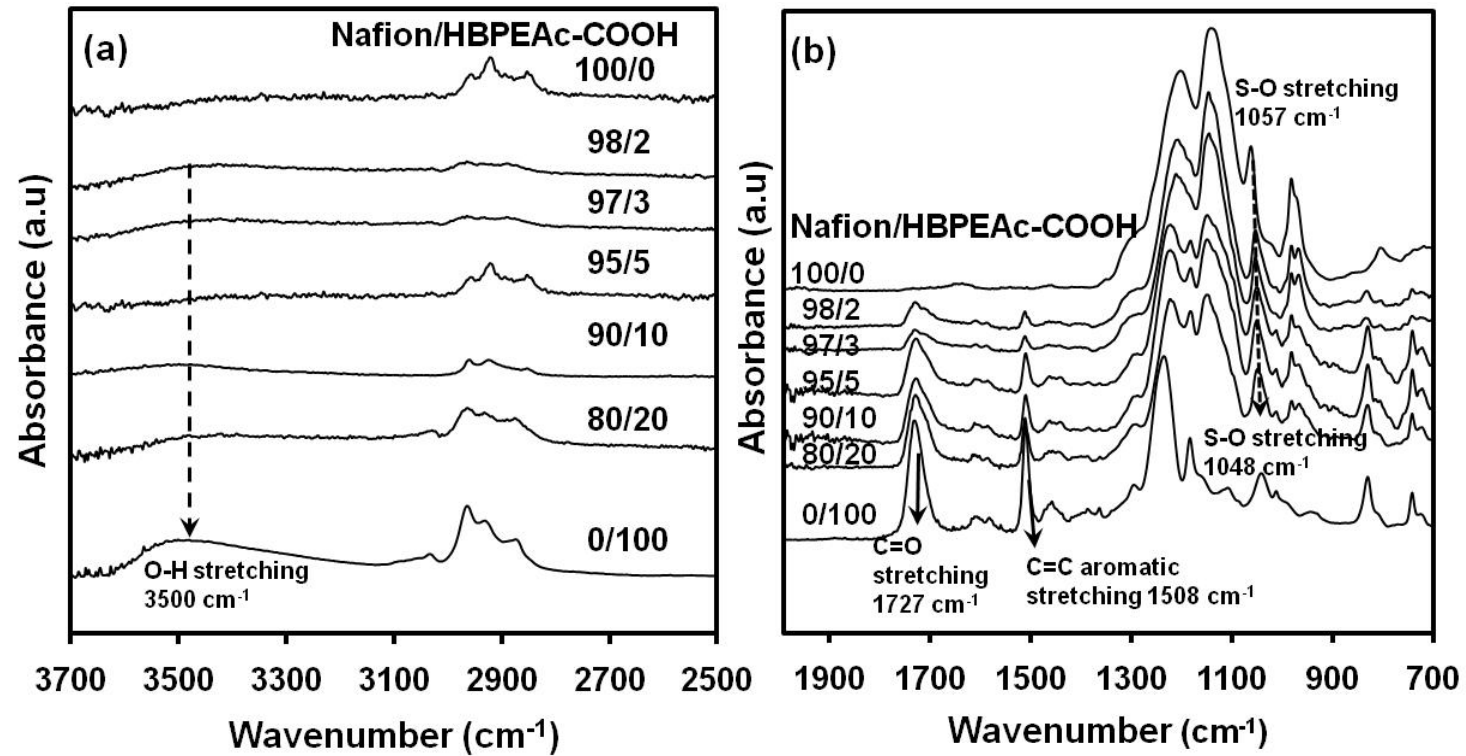

Figure 6(b) exhibits the FTIR spectrum of neat Nafion membrane showing two strong bands at $1,200 \mathrm{~cm}^{-1}$ and $1,140 \mathrm{~cm}^{-1}$, attributable to the $\mathrm{C}-\mathrm{F}$ asymmetric and symmetric stretching vibrations of the main chain, respectively, along with the $\mathrm{C}-\mathrm{F}$ stretching vibrations from the side chains of Nafion at $980 \mathrm{~cm}^{-1}$. As expected, there is no movement of these peaks upon incorporation of the HB polyester. Similarly, the C-F bending mode at $967 \mathrm{~cm}^{-1}$ and $-\mathrm{CF}_{2}$ rocking mode at $625 \mathrm{~cm}^{-1}$ remained stationary upon impregnation of the HB polyester in Nafion. Together with the SSNMR results, it is reasonable to infer that in the dried state there is little or no influence on the reactivity on the fluoropolymer components of the Nafion backbone upon inclusion of the HB polyester into the ionic domains.

The FTIR spectrum from neat HBPEAc-COOH exhibits a number of characteristic bands; specifically the peak at $1,727 \mathrm{~cm}^{-1}$ arising from the carbonyl stretching, whereas the peak at $1,508 \mathrm{~cm}^{-1}$ associated with the $\mathrm{C}=\mathrm{C}$ stretching of the aromatic rings. The bands at $1,230 \mathrm{~cm}^{-1}$ and $1,190 \mathrm{~cm}^{-1}$ correspond to the $\mathrm{C}-\mathrm{O}-\mathrm{C}$ stretching of cyclic ether linkages of HBPEAc-COOH. The $830 \mathrm{~cm}^{-1}$ and $740 \mathrm{~cm}^{-1}$ peaks are associated with the $\mathrm{C}-\mathrm{H}$ bending and $\mathrm{C}=\mathrm{C}$ aromatic out-of-plane bending vibrations, respectively. The $\mathrm{C}=\mathrm{O}$ band of the neat $\mathrm{HB}$, which is located at $1,727 \mathrm{~cm}^{-1}$, shows a minor shift upon impregnation for about $2 \sim 3 \mathrm{~cm}^{-1}$ which is below the spectral resolution of $4 \mathrm{~cm}^{-1}$ and thus it is inconclusive. 
In the case of neat Nafion, the $\mathrm{S}-\mathrm{O}$ band, located at $1,057 \mathrm{~cm}^{-1}$, is slightly lower than that of the dried Nafion $\left(1,061 \mathrm{~cm}^{-1}\right)$ [18] which implies that some bound water might be present in the Nafion at $100{ }^{\circ} \mathrm{C}$. According to Falk, this symmetric S-O stretching band shifts to a lower wavenumber upon hydration engaging in the water-water and/or water-ion interactions [19]. However, the $\mathrm{S}-\mathrm{O}$ band of neat Nafion is noticeably shifted from $1,057 \mathrm{~cm}^{-1}$ to $1,048 \mathrm{~cm}^{-1}$ in the impregnated Nafion. The shifting of the $\mathrm{S}-\mathrm{O}$ band to a lower wavenumber upon HB impregnation suggests the occurrence of complexation of $\mathrm{S}-\mathrm{O}$ possibly with $\mathrm{O}-\mathrm{H}$ of carboxylic acid group of the $\mathrm{HB}$ supramolecules bridging through some bound water molecules. A natural question is why the $\mathrm{C}=\mathrm{O}$ band shows little or no movement. It may be hypothesized that when the bound water in $\mathrm{HB}$ interacts with $\mathrm{S}-\mathrm{O}$ of Nafion, some $\mathrm{C}=\mathrm{O}$ bonds may be freed up, thereby contributing to a spectral red shift. This may be compensated by the blue shift of $\mathrm{C}=\mathrm{O}$ if inter-species complexation were to occur between the carboxylic groups of HBPEAc-COOH and the sulfonate groups of Nafion, e.g., inter-species hydrogen bonding.

In order to quantify the estimated amount of HBPEAc-COOH incorporated in the Nafion membrane, two different FTIR approaches were employed. Note that the FTIR spectra were collected after wiping off any residual HBPEAc-COOH that might be deposited on the surface of Nafion membranes. After drying, the impregnated membrane was photocured in accordance with the procedure described in the experimental section. The first approach focuses on the peak (position) shift of S-O band with HB polyester content and the second approach utilizes the integrated area under the $\mathrm{C}=\mathrm{O}$ and $\mathrm{C}=\mathrm{C}$ aromatic peak at $1,727 \mathrm{~cm}^{-1}$ and $1,508 \mathrm{~cm}^{-1}$ to determine the amount of $\mathrm{HBPEAc-COOH}$ in Nafion.

Figure 7. (a) Plot of wavenumber of the $\mathrm{S}-\mathrm{O}$ stretching band of FTIR as a function of HBPEAc-COOH amount demonstrating a considerable shift of the $\mathrm{S}-\mathrm{O}$ band to a lower wavenumber (i.e., about $9 \mathrm{~cm}^{-1}$ ) implying inter-species hydrogen bonding interaction of the carboxylic acid of HBPEAc-COOH with the sulfonic acid terminal group of Nafion; (b) quantification of the estimated amount of HBPEAc-COOH present in Nafion membrane based on the integrated area under the curve of the FTIR spectra from $\mathrm{C}=\mathrm{O}$ and $\mathrm{C}=\mathrm{C}$ aromatic stretching bands. The dashed line represents the actual amount of $\mathrm{HB}$ incorporated in the ideal situation.
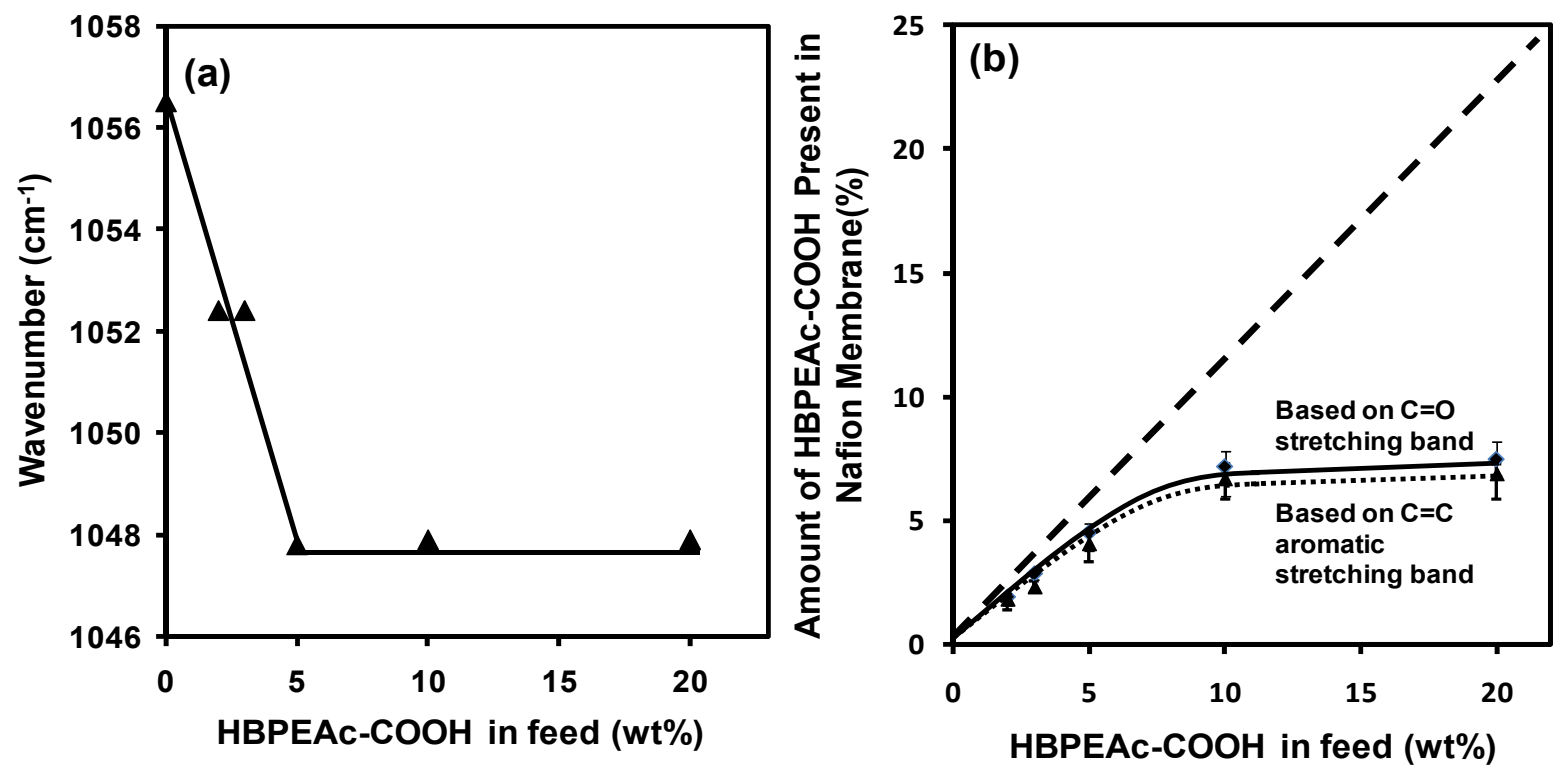
As shown in Figure $7(\mathrm{a})$, the $\mathrm{S}-\mathrm{O}$ band at $1,057 \mathrm{~cm}^{-1}$ moves to a lower wavenumber (i.e., about $9 \mathrm{~cm}^{-1}$ ) with increasing loading level of HBPEAc-COOH in Nafion. This moving trend levels off at about 5-10 wt \% of HB polyester in the feed suggesting that the impregnation of HBPEAc-COOH into the Nafion ionic domain has reached a saturation level. In the second method, the area under the curves of $\mathrm{C}=\mathrm{O}$ and $\mathrm{C}=\mathrm{C}$ aromatic band were calculated as described before. The dashed line indicates an ideal situation, where the amount of HBPEAc-COOH in the impregnated membrane conforms exactly to that of the feed. As seen in Figure 7(b), the estimated amount of HBPEAc-COOH that is incorporated into the Nafion conforms relatively well with the ideal situation up to $5 \mathrm{wt} \%$ and then it saturates out after $10 \mathrm{wt} \%$. Hence, the estimated amount of incorporated HBPEAc-COOH was estimated to be about $7 \mathrm{wt} \%$. Based on the FTIR investigation, it may be concluded that the amount of HB polyester incorporated is about 5 to $7 \mathrm{wt} \%$ which is in good accord with the relative intensity quantification by SSNMR. The FTIR and SSNMR studies revealed that the Nafion membrane was indeed impregnated with the HB polyester network, through occupying the hydrophilic packets of the membrane and interacting with the $\mathrm{SO}_{3} \mathrm{H}$ groups.

Based on the observed SSNMR and FTIR findings, a schematic drawing in Figure 8 is presented to hypothesize a plausible mechanism of aggregated structure within the ionic domains of the HB impregnated Nafion. It seems that the specific interactions such as inter-species hydrogen bonding between the $-\mathrm{COOH}$ of $\mathrm{HBPEAc}-\mathrm{COOH}$ and the $-\mathrm{SO}_{3} \mathrm{H}$ of Nafion is prevalent. Moreover, the HB polyester networks appear isolated from the surrounding fluorocarbon matrix, having virtually little or no direct interaction with the fluorocarbons except for contributing to a slight gain in mobility of the backbone chains. The impregnated HB supramolecules will take away some of the space within the ionic domains and thus limited space will be available for water molecules to occupy.

Figure 8. Schematic drawing of the ionic domain of the Nafion membrane before and after impregnation with HBPEAc-COOH showing the isolated cured HB polyester network from the fluorocarbon matrix.

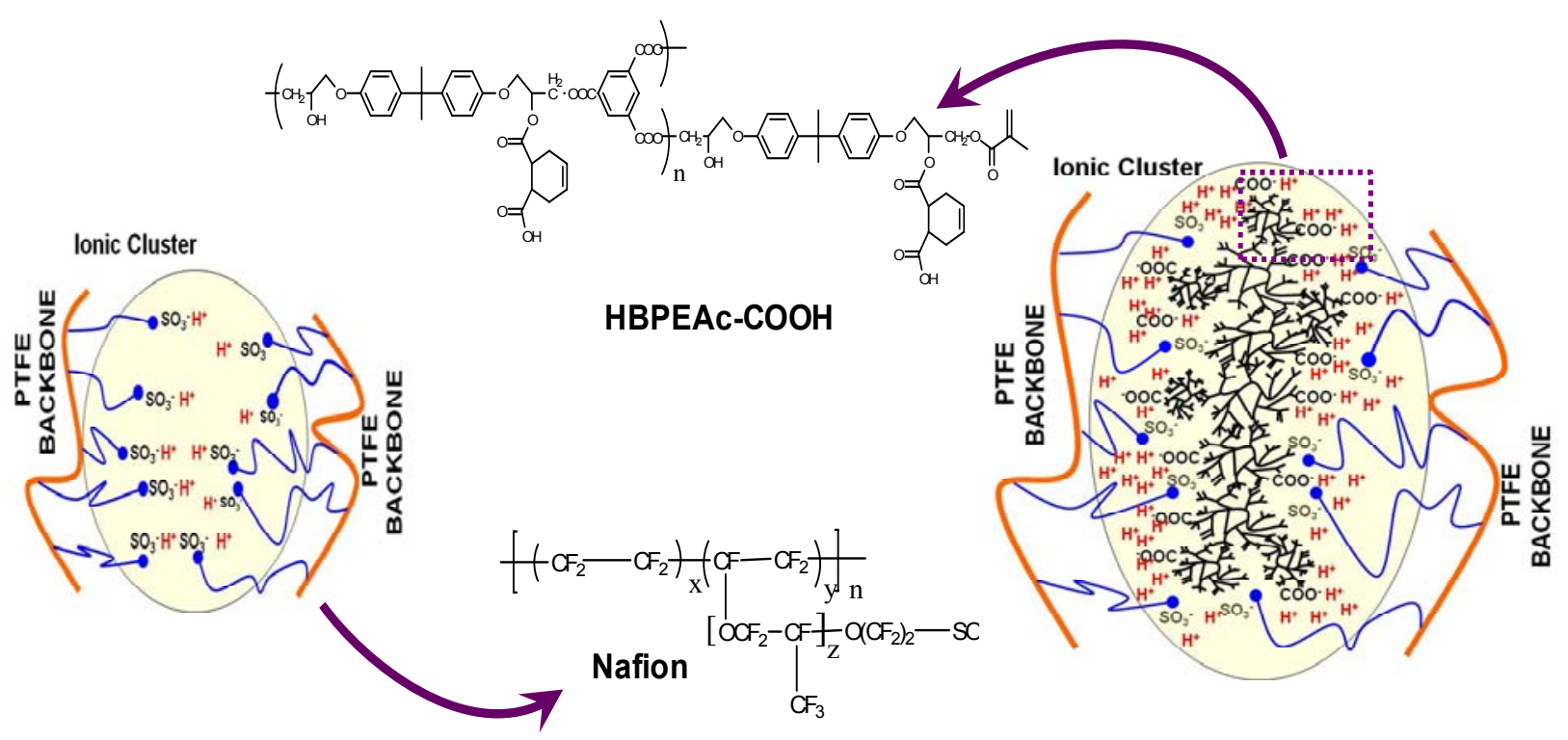

Figure 9(a) shows the plot of water uptake as a function of soaking time for both neat and impregnated membranes at room temperature. The water uptake of neat Nafion in acid form is 
crucial [20] and was found to absorb up to $37 \mathrm{wt} \%$. Elliot et al. [21] demonstrated the swelling of the ionic domains by water in turn plasticizes the fluorocarbon matrix. As shown in Figure 9(a), this swelling can be suppressed considerably by incorporating HBPEAc-COOH into the Nafion, i.e., the water uptake drops from $15 \mathrm{wt} \%$ to $10 \mathrm{wt} \%$ as the composition of $\mathrm{HBPEAc-COOH}$ in feed increases from $3 \mathrm{wt} \%$ to $10 \mathrm{wt} \%$. Note that the above water uptake experiment is important to evaluate the dimensional stability characteristics, since the physical dimensions of both impregnated membrane and neat Nafion are difficult to compare due to the severe warping displayed especially by the pure Nafion.

Figure 9. (a) Plot of water uptake as a function of soaking time for both neat and impregnated membranes at room temperature showing considerable reduction in water uptake; (b) graph of $\lambda$ (moles of $\mathrm{H}_{2} \mathrm{O}$ per mole of $\mathrm{SO}_{3}{ }^{-}$) as a function of HBPEAc-COOH composition (after soaking for $24 \mathrm{~h}$ ), illustrating significant reduction of water molecules from $\lambda=\sim 22$ (neat Nafion) to $\lambda=\sim 7$. The IEC curve shows an increment trend (i.e., proton storage capacity) with HBPEAc-COOH loading. Insets show photograph of neat Nafion membrane (10 $\mathrm{mm}$ in width and $22 \mathrm{~mm}$ in length) exhibiting severe warpage upon hydration and significantly less warpage in the $10 \% \mathrm{HBPEAc-COOH}$ impregnated Nafion membrane demonstrating improved dimensional stability.
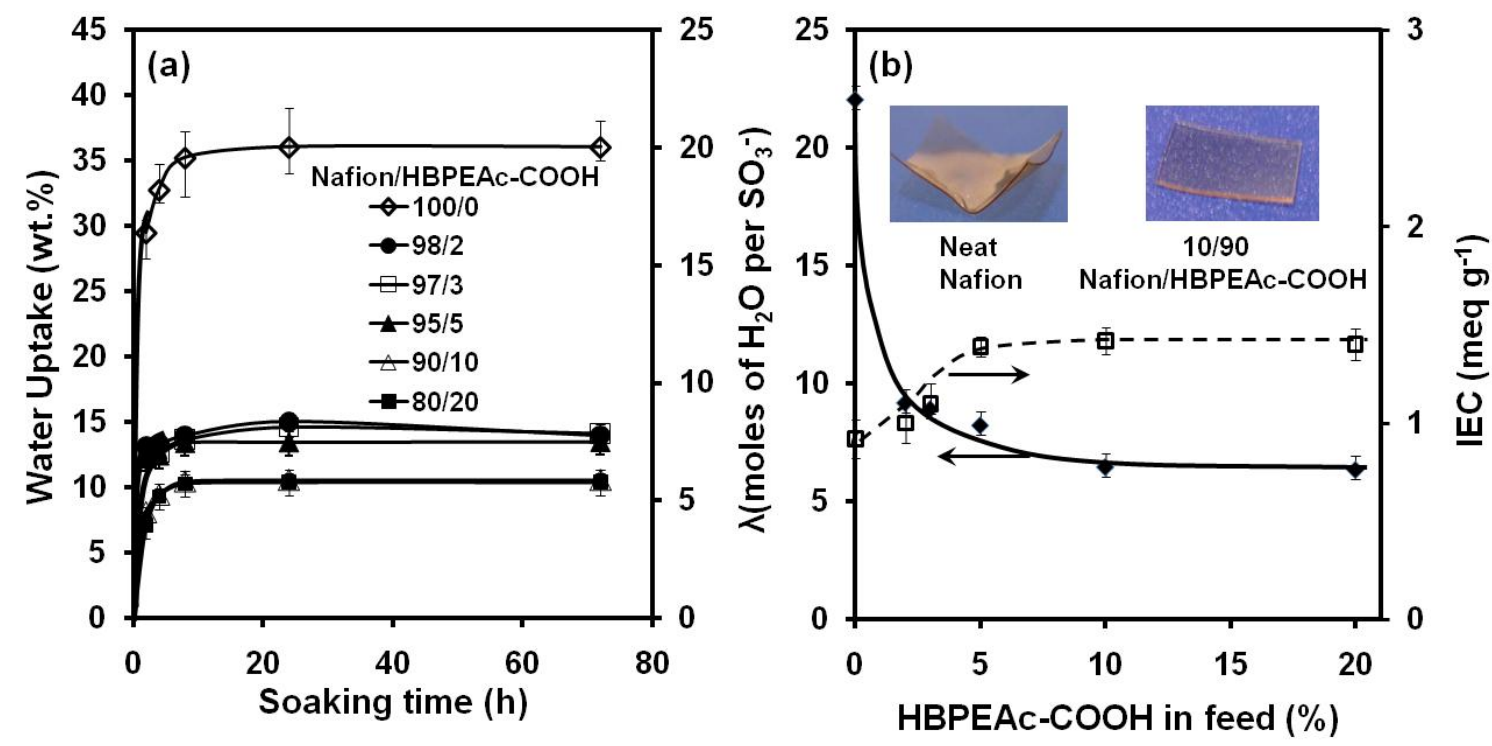

In Figure 9(b) is shown the number of moles of water per mole of sulfonic acid site $(\lambda)$ as a function of HBPEAc-COOH composition in feed. In neat Nafion-acid, up to 22 moles of water are absorbed per mole of sulfonic acid site after $24 \mathrm{~h}$ of soaking; this number increases with water temperature [22]. However, in the case of the impregnated membrane, only seven moles of water can be absorbed by one sulfonic acid site as the number of moles of water saturates out at $\sim 10 \mathrm{wt} \%$ of HBPEAc-COOH in feed. According to Paddison et al. [23], the ab initio calculation for the elucidation of the proton transport mechanism of Nafion revealed that only $6 \mathrm{H}_{2} \mathrm{O} / \mathrm{SO}_{3}{ }^{-}$are needed to exhibit the complete proton dissociation resulting in efficient proton conduction. Upon hydration, the fluorocarbon matrix undergoes reorganization, which imposes large internal stresses on the membrane resulting in warping as depicted in the inset right picture of Figure 9(b). Consequently lower swelling capability and minimized internal stress within the impregnated membrane leads to better dimensional stability upon 
hydration as seen in the inset left picture of Figure 9(b). It can be envisioned that the sulfonic acid sites have been surrounded with HBPEAc-COOH molecules and this shielding of the ionic sites lowers the hydrophilicity of the membrane. The formation of the cured HB polyester network has contributed to improved dimensional stability of the Nafion membrane.

Furthermore, Figure 9(b) demonstrates that the ion exchange capacity (IEC) of impregnated membranes exceeds the IEC of neat Nafion, i.e., $\sim 0.92 \mathrm{meq} \mathrm{g}^{-1}$, showing increasing trend of the IEC value with addition of HB. The IEC for the impregnated membrane, however, saturated out at $5 \mathrm{wt} \%$ of HB in feed with a maximum value of $\sim 1.41 \mathrm{meq}^{-1}$. The enhancement of IEC may be attributed to the increase in the number of acidic protons, i.e., the carboxylic acid sites in HB within the ionic clusters.

Next, DMA was performed to mimic the viscoelastic properties of the impregnated membrane by analyzing the relaxation temperature of the ionic domain, i.e., $\alpha$-relaxation. Figure 9 shows the plots of storage modulus, E' and tan $\delta$ curves versus temperature for 10\% HBPEAc-COOH impregnated Nafion and neat Nafion membranes. In the neat Nafion-acid, there are three relaxations termed $\gamma, \beta$ and $\alpha$-relaxations in ascending order of temperature from -130 to $150{ }^{\circ} \mathrm{C}$ that were observed at $-70,15$ and $100{ }^{\circ} \mathrm{C}$ respectively. According to Kyu et al. [24], these $\gamma$-, $\beta$ - and $\alpha$-relaxations can be assigned to the $-\mathrm{CF}_{2}$ local motions, glass transition of Nafion matrix and glass transition of the ionic domain, respectively. Underwater stress relaxation of neat Nafion in acid and sodium forms showed that the $\alpha$-relaxation temperature is profoundly affected by the presence of water in the ionic regions [25]. One drawback of the neat Nafion-acid form is that the hydrophilic ionic domains become extremely mobile above this $\alpha$-relaxation temperature and thus the interconnected channels may eventually be disrupted upon prolonged exposure to elevated temperature.

The impregnation of Nafion by HBPEAc- $\mathrm{COOH}$ raised the $\alpha$-relaxation temperature from 100 to $130{ }^{\circ} \mathrm{C}$, thereby improving the thermal stability of the membrane. This improved $\alpha$-relaxation temperature may be due to the inter-species hydrogen bonding interaction and/or the chemical crosslinking of the supramolecules contributing to the enhanced thermal stability as demonstrated earlier in the FTIR study. In the inset of Figure 10, are shown the pictures of membrane samples taken after DMA experiments at $150{ }^{\circ} \mathrm{C}$. It is striking to witness the brownish color of neat Nafion, i.e., the manifestation of thermal instability of protonated ionic domains, turned into light beige (i.e., inherent Nafion color) in the impregnated membrane, implying improved thermal stability at $150{ }^{\circ} \mathrm{C}$.

With descending temperature, an additional relaxation peak can be discerned at $\sim 90{ }^{\circ} \mathrm{C}$, Figure 10 . This peak temperature is analogous to the DSC $\mathrm{T}_{\mathrm{g}}$ of cured neat HB polyester and thus it is reasonable to assign it to the glass transition of cured HBPEAc-COOH within the impregnated membrane. The original $\beta$-relaxation peak of neat Nafion, i.e., the glass transition of the fluorocarbon backbone of Nafion, slightly decreases from 15 to $5{ }^{\circ} \mathrm{C}$ (Figure 10), but the tan $\delta$ value becomes more pronounced. However, it should be pointed out that this $\beta$-relaxation peak is considerably overlapped with the onset of the $\mathrm{T}_{\mathrm{g}}$ peak of HB supramolecules. This overlap might have contributed to the enhanced movement of the fluorocarbon backbone chains, thereby increasing intensity of the $\beta$-relaxation peak. Recall the finding of the SSNMR of ${ }^{19} \mathrm{~F}-{ }^{13} \mathrm{C} \mathrm{CP} / \mathrm{MAS}$ in Figure 4 that shows virtually no reactivity between the HB supramolecules and the fluorocarbon backbone matrix in the dried state, except the narrowing of the linewidth of the $-\mathrm{CF}_{2}$ backbone of Nafion. This SSNMR narrowing indicates that the fluorocarbon chain is becoming more mobile, which is consistent with the enhanced strength of the mechanical $\beta$-relaxation peak caused by the HB impregnation (Figure 10). 
Figure 10. Change of storage modulus and loss tangent as a function of temperature of neat Nafion-acid form (solid line) and 10\% HBPEAc-COOH impregnated Nafion membrane (dashed line). An additional relaxation peak, attributable to the $\mathrm{T}_{\mathrm{g}}$ of the cured HBPEAc-COOH, appears in the impregnated membrane at around $\sim 90{ }^{\circ} \mathrm{C}$. The inset photographs show relative thermal stability of the impregnated membrane showing light beige as compared to the dark brownish color of neat Nafion-acid after dynamic mechanical analysis (DMA) experiments at $150{ }^{\circ} \mathrm{C}$. The sample dimension was $10 \mathrm{~mm}$ in width $\times 25 \mathrm{~mm}$ in length.

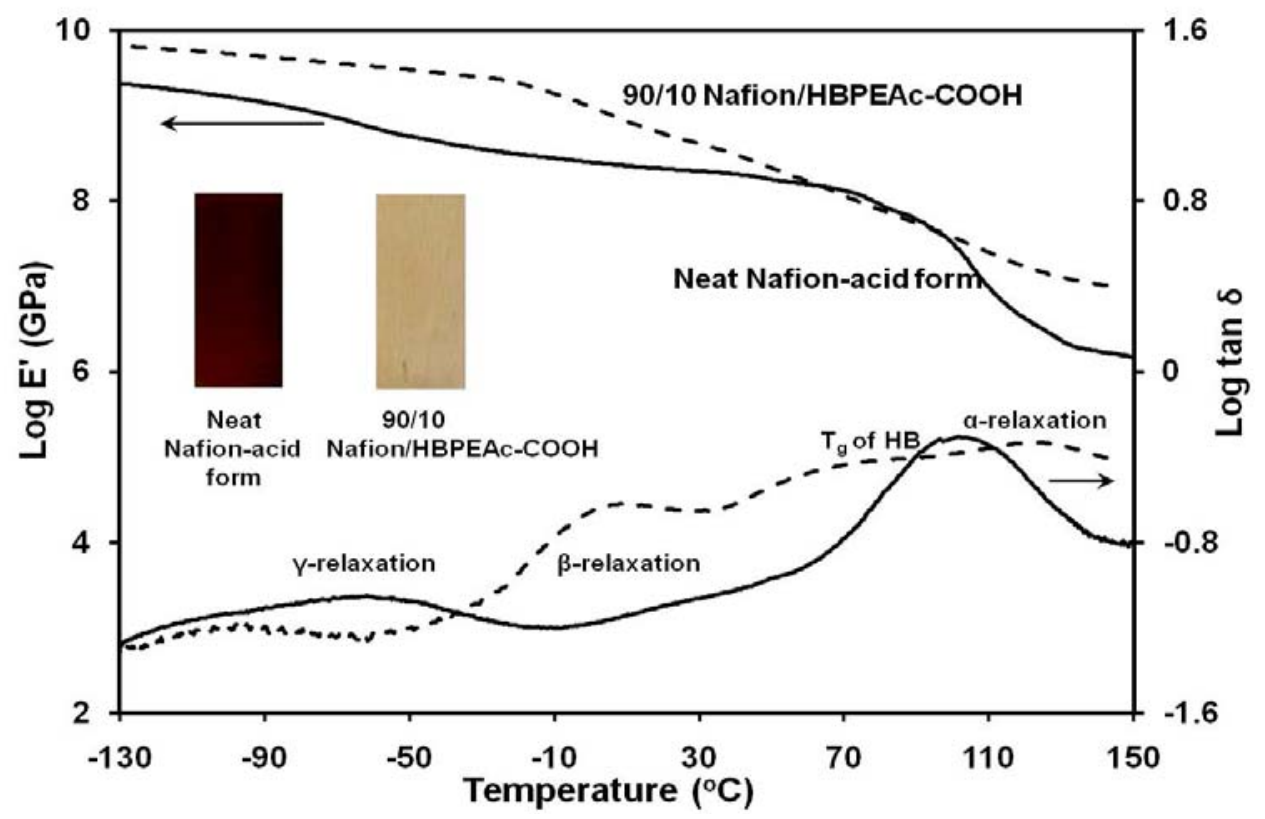

Another important observation is the increase in the storage modulus values of the impregnated membrane. As can be seen in Figure 10, the modulus of the HBPEAc-COOH impregnated Nafion membrane increases over one order of magnitude at lower temperatures, which may be attributed to the HBPEAc-COOH network. Although both storage moduli of impregnated Nafion and neat Nafion membranes decrease with temperature, the crosslinked HB network yielded a higher storage modulus at elevated temperatures $\left(100 \sim 130^{\circ} \mathrm{C}\right)$.

In order to determine whether or not there is any improvement in the proton transport of the HBPEAc-COOH impregnated membrane over neat Nafion, proton conductivity measurements were conducted by AC impedance fuel cell tests at the humidity levels of $100 \% \mathrm{RH}$ and $74 \% \mathrm{RH}$ as a function of temperature. Figure 11(a,b) illustrate log-log plot of complex impedance $\left(Z^{*}=Z^{\prime}-i Z^{\prime \prime}\right)$ versus frequency plots obtained for the 90/10 Nafion/HBPEAc-COOH impregnated membrane at $74 \% \mathrm{RH}$. The experiment at $100 \% \mathrm{RH}$ was not feasible beyond $115{ }^{\circ} \mathrm{C}$ with the current instrument due to the temperature limitation. The storage impedance $\left(Z^{\prime}\right)$ obtained shows a sigmoidal reduction of impedance values with frequency, whereas the loss impedance $\left(Z^{\prime \prime}\right)$ reveals a corresponding peak around $\sim 20 \mathrm{~Hz}$ and slightly shifted to higher frequencies with temperature. The reduction of storage impedance with frequency implies an increasing ionic (proton) resistance of the impregnated electrolyte membrane. It was found that the complex impedance plots of the impregnated membrane 
at $74 \% \mathrm{RH}$ showed a similar trend to that at $100 \% \mathrm{RH}$, except for slightly different AC impedance values (data not shown).

Next, the Cole-Cole plots were constructed over the frequency range of $0.1 \mathrm{~Hz}-10 \mathrm{kHz}$. Figure 11(c) illustrates the Cole-Cole plot of $10 \mathrm{wt} \% \mathrm{HBPEAc}-\mathrm{COOH}$ impregnated membrane at $74 \%$. The first intersection of the plot at the $x$-axis is denoted as $\mathrm{R}_{\mathrm{s}}$ indicating the contact resistance between the electrolyte membrane and the catalyst layer; known as the solution resistance. The diameter of the semi-circular plot, denoted by $\mathrm{R}_{\mathrm{p}}$ is taken as the overall cell resistance or polarization resistance [26]. The magnitude of $R_{p}$ represents the true resistance from which the conductivity value may be evaluated. Conductivity, $\sigma$, was then calculated in accordance with Equation (6) as explained in the experimental section. An equivalent circuit of the cell may be represented by a resistor in series with a parallel circuit containing a capacitor and a resistor.

Figure 11. Plots of (a) log-log storage impedance versus frequency and (b) log-log loss impedance versus frequency of 90/10 Nafion/HBPEAc-COOH at 74\% RH measured from 30 to $100{ }^{\circ} \mathrm{C}$ with $10{ }^{\circ} \mathrm{C}$ increment; and (c) Cole-Cole plots of $90 / 10 \mathrm{Nafion} / \mathrm{HBPEAc-COOH}$ impregnated membranes generated at $74 \% \mathrm{RH}$. The diameter of semi-circular plots shrinks with temperature due to lowering of the overall cell resistance.
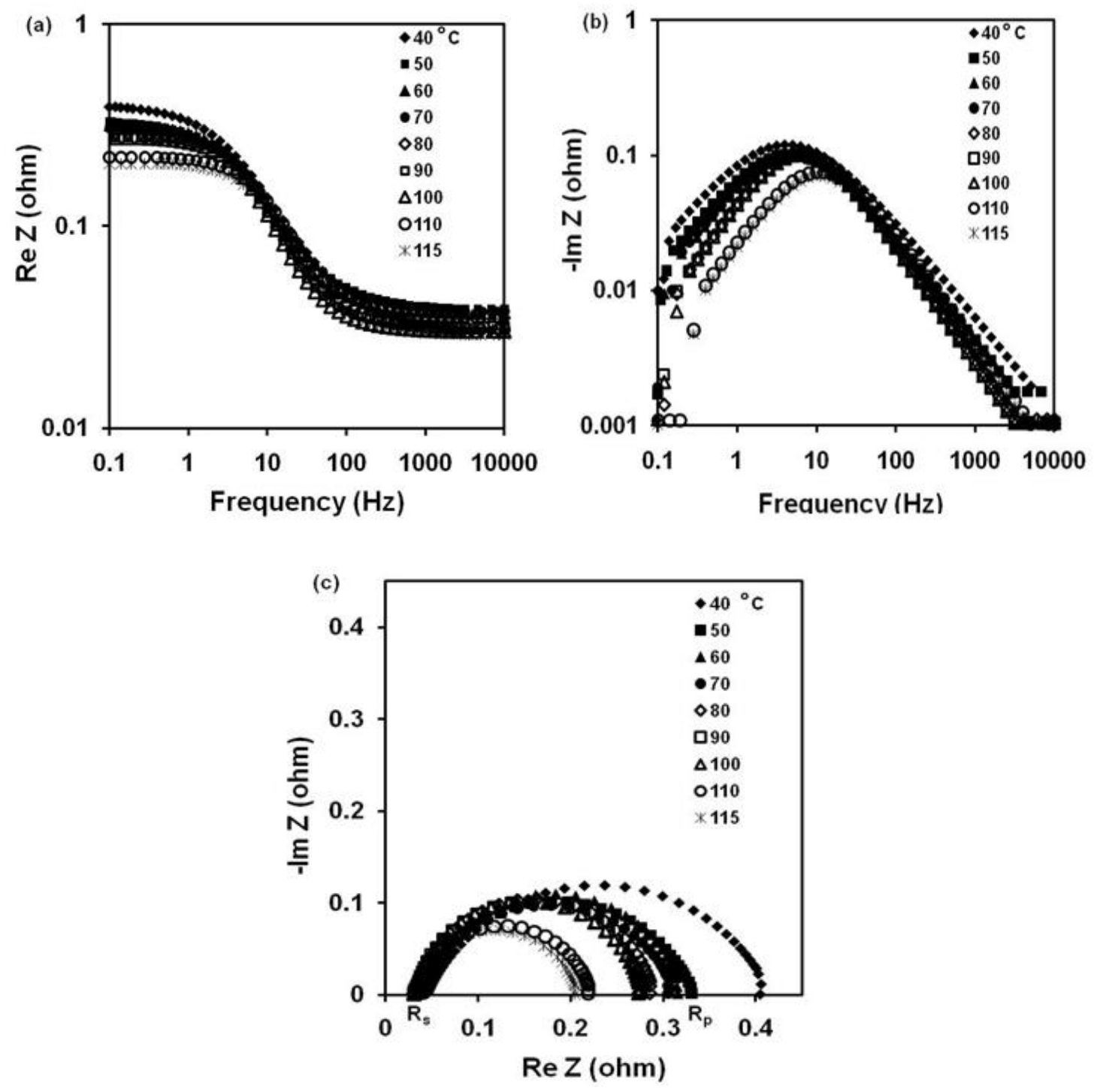
Figure 12 shows the plots of proton conductivity as a function of temperature from 70 to $115{ }^{\circ} \mathrm{C}$ at $74 \% \mathrm{RH}$ of neat Nafion and impregnated membranes. The proton conductivity of neat Nafion is the highest at $80^{\circ} \mathrm{C}$, but gradually declined with increasing of temperature. Since the proton conductivity of Nafion consists of both proton $\left(\mathrm{H}^{+}\right)$and hydronium (e.g., $\mathrm{H}_{3} \mathrm{O}^{+}, \mathrm{H}_{5} \mathrm{O}_{2}{ }^{+}$) transport, the loss of water above the boiling temperature can significantly reduce the overall proton conductivity [27] of the hydrophilic clusters. Further increment of temperature results in possible disruption of the percolated ionic channels and the ionic clusters become more isolated thereby reducing the efficiency of proton to conduct.

Figure 12. Proton conductivity plots of neat Nafion and impregnated membrane as a function of temperature at $74 \% \mathrm{RH}$. Proton conductivity of neat Nafion plummets beyond $80{ }^{\circ} \mathrm{C}$ while the conductivity value of the impregnated membrane continues to increase with temperature. Notice that the proton conductivity of the impregnated membranes is improved for about $30 \%$ over that of neat Nafion at $115{ }^{\circ} \mathrm{C}$.

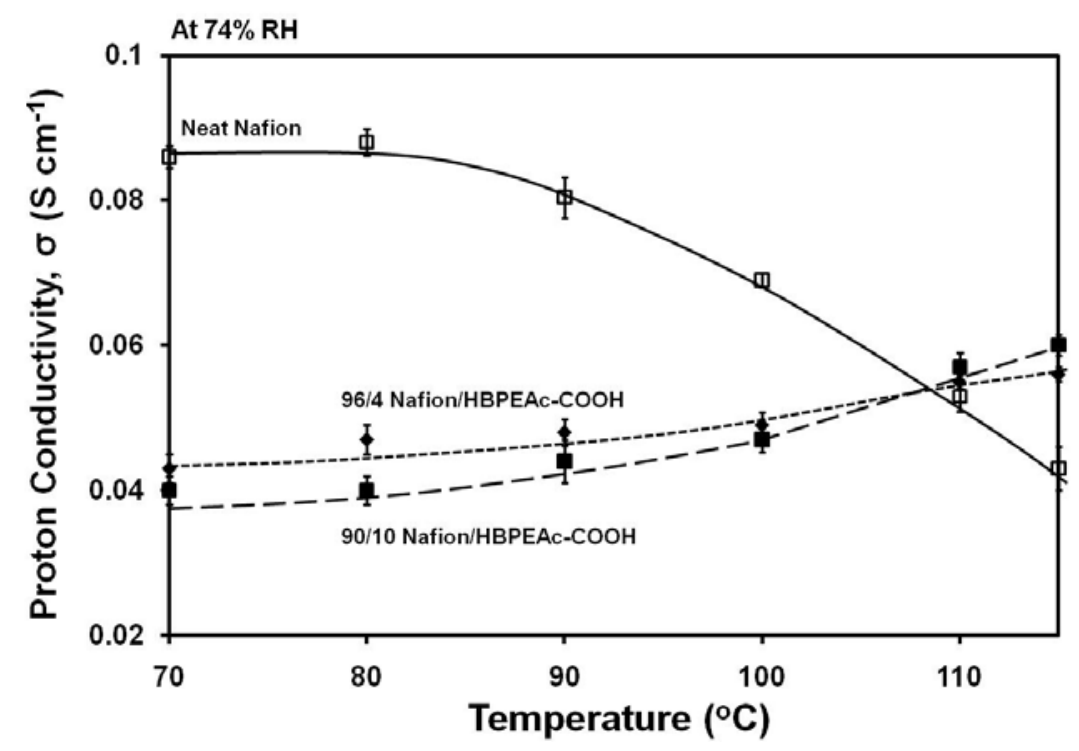

The impregnated membranes with $10 \mathrm{wt} \%$ of $\mathrm{HB}$, on the other hand, exhibits an increasing conductivity trend with temperature afforded by the acidic protons from the pendant carboxylic groups from the HB supramolecules, which gained higher mobility when temperature is raised. The conductivity value of the impregnated membrane increased from $0.040 \mathrm{~S} \mathrm{~cm}^{-1}$ at $80{ }^{\circ} \mathrm{C}$ to $0.056 \mathrm{~S} \mathrm{~cm}^{-1}$ at $115{ }^{\circ} \mathrm{C}$ and at $74 \% \mathrm{RH}$, which eventually exceeded that of the neat Nafion $\left(\sigma=0.043 \mathrm{~S} \mathrm{~cm}^{-1}\right.$ at $115^{\circ} \mathrm{C}$ and at $74 \% \mathrm{RH}$ ). This observation is not surprising in view of the fact that a sizable portion of the Nafion ionic domain was occupied by the HB networks, which in turn reduced the water uptake. Incorporation of hyperbranched polyesters within the ionic clusters lowers water uptake and therefore lowering conductivity in the impregnated membrane. By reducing the $\mathrm{HB}$ amount to $4 \mathrm{wt} \%$, more water molecules can be accommodated with the ionic domains and thus the proton conduction can increase slightly at low temperatures as compared with the $10 \mathrm{wt} \%$ sample. At elevated temperature above $100{ }^{\circ} \mathrm{C}$, it shows the proton conductivity behavior that is intermediate between the neat Nafion and the $10 \mathrm{wt} \%$ impregnated membrane.

Of particular importance is that the proton conduction of the HBPEAc-COOH impregnated membrane showed an increasing trend that eventually exceeded that of neat Nafion at 110 and $115^{\circ} \mathrm{C}$, 
even though with only slight improvement in the proton conductivity value. It can be anticipated that the hydrogen bonded carboxylic acids groups present in the ionic clusters/HBPEAc-COOH networks will be ionized with water vapor when the temperature is raised, resulting in free hydronium ions that ultimately promotes the proton conduction process under the minimal water level. Hence, it is reasonable to infer that the proton conducting of the impregnated membrane at elevated temperatures is becoming less dependent on the free water molecules but more on the ionized protons of the carboxylic acid groups. Although the present proton conductivity measurement is limited to $115{ }^{\circ} \mathrm{C}$ due to the present instrumental configuration, the impregnated membrane is demonstrated to be thermally more stable up to the experimental temperature of $150{ }^{\circ} \mathrm{C}$ as manifested in the previous DMA experiment.

There is a concern that the HB polyester in Nafion membrane may undergo hydrolysis, which is prevalent in most common polyesters. Nafion itself may suffer to some level of membrane deterioration upon prolonged or repeated usage in proton fuel cells due to the formation of peroxide radical originating from the platinum/carbon supported catalyst [28]. HB polyesters might as well be susceptible to such radical attack in the actual proton fuel cell operation. Thus, neat Nafion and HB impregnated membranes were subjected to cyclic AC impedance measurements in proton fuel cell environment by heating and cooling from 30 to $100{ }^{\circ} \mathrm{C}$ at $100 \% \mathrm{RH}$ for a total of 5 cycles. Figure 13 exhibits the heating and cooling cycles of neat Nafion and impregnated membrane and there is a subtle proton conductivity hysteresis between the heating and cooling cycles of neat Nafion (only the first and fifth cycles are shown for clarity) starting from $70{ }^{\circ} \mathrm{C}$ up to $100{ }^{\circ} \mathrm{C}$. However, the $\mathrm{HB}$ impregnated Nafion reveals little or no change in the proton conductivity up to the 5 cycles tested, i.e., a total of $160 \mathrm{~h}$ of operation. Contrary to the general perception on possible hydrolysis of conventional polyester, the present AC measurements on the impregnated membranes show no sign of deterioration in performance in proton conductivity in the repeated cycles under the true proton fuel cell conditions up to $100{ }^{\circ} \mathrm{C}$.

Figure 13. Heating and cooling cyclic AC impedance measurements of neat Nafion and impregnated membrane at $100 \%$ RH demonstrating the lowering of the proton conductivity hysteresis of neat Nafion after each cycle. The impregnated membrane, however, shows relatively consistent proton conductivity after all five cyclic measurements.

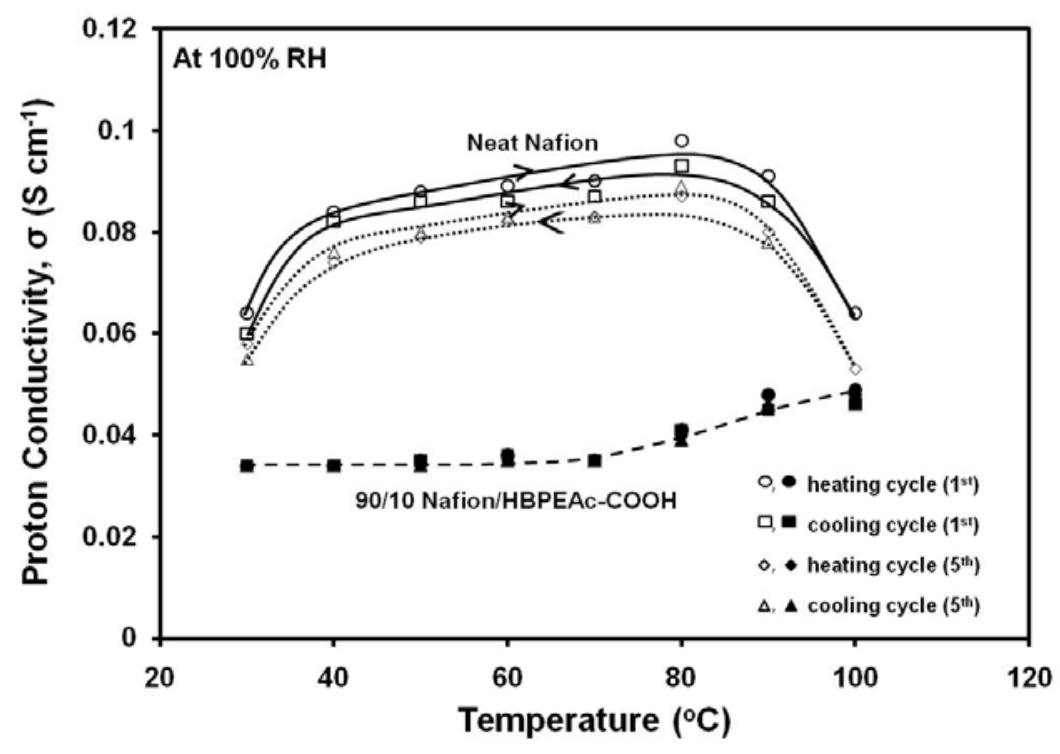


In order to check the potential hydrolysis of polyester, we acquired the FTIR scans on the HB impregnated membranes before and after the cyclic AC impedance measurements. Contrary to the general perception, we did not find any noticeable difference in FTIR spectra before and after the proton fuel cell tests, implying the chemical stability of the HB impregnated membranes up to $100{ }^{\circ} \mathrm{C}$ (Figure 14). On the basis of combined cyclic AC impedance measurement and the FTIR investigation, it is reasonable to conclude that the photocured HB polyester network within the Nafion ionic domains appears chemically stable under the conditions of the present proton fuel cell operation at $100{ }^{\circ} \mathrm{C}$ for $160 \mathrm{~h}$.

Figure 14. FTIR spectra of 90/10 Nafion/HBPEAc-COOH (a) before and (b) after subjected to the cyclic AC impedance proton fuel cell measurements for a total of $160 \mathrm{~h}$. These spectra were obtained at room temperature.

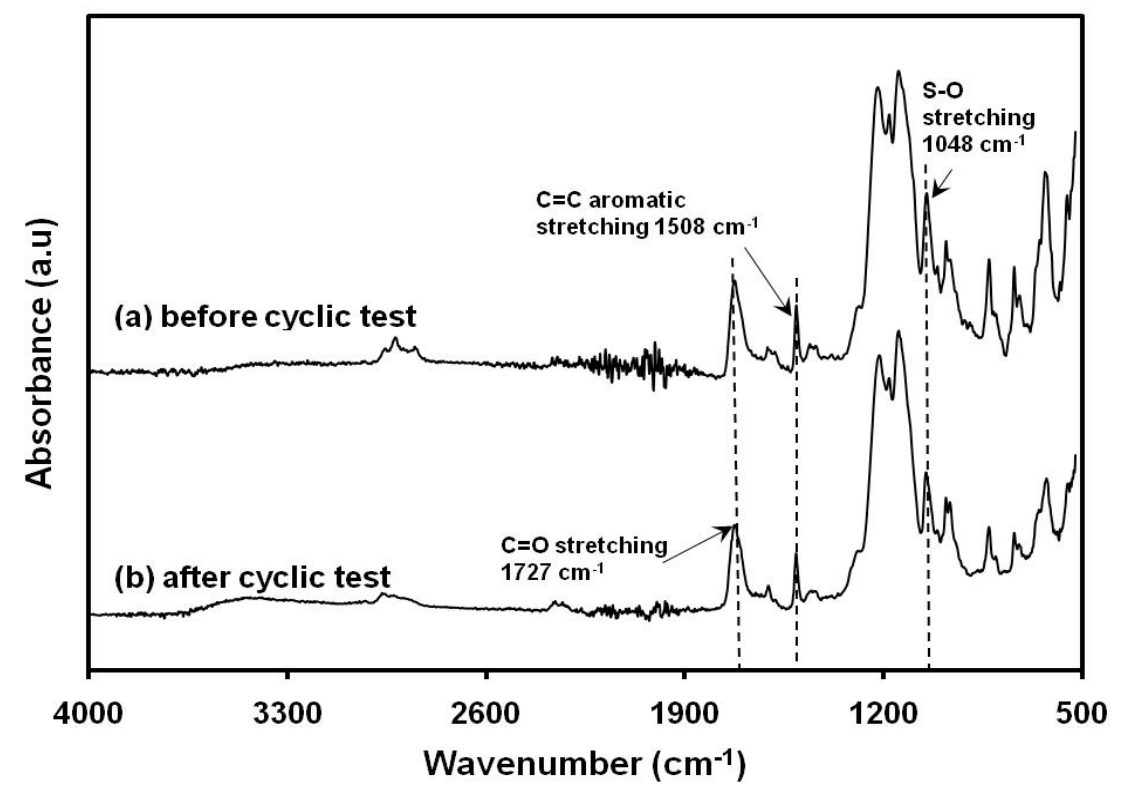

\section{Experimental Section}

\subsection{Materials and Sample Preparation}

Nafion 115 membranes with equivalent weight of 1,100 in its original acid form were purchased from Fuel Cell Store. In accordance with the literature procedure [11], as-received Nafion membranes were first pretreated by boiling in 3\% hydrogen peroxide $\left(\mathrm{H}_{2} \mathrm{O}_{2}\right)$ solution for $2 \mathrm{~h}$ and subsequently rinsed in boiling deionized water. The membranes were then boiled in $0.5 \mathrm{M}$ sulfuric acid $\left(\mathrm{H}_{2} \mathrm{SO}_{4}\right)$ and rinsed again in boiling deionized water (at least $1 \mathrm{~h}$ for each step) to remove excess sulfuric acid, and then dried in a vacuum oven and kept in a dessicator prior to each impregnation process.

The HB polyester was synthesized from polyaddition of bisphenol-A-diglycidyl ether (BPGE) with trimesic acid (TMA) and methacrylic acid (MA), by adding cis-1,2,3,6-tetrahydrophthalic anhydride (THPA), triphenylphosphine (TPP) and hydroquinone (HQ) having pendant methacryloyl and carboxyl groups. The molecular weight and polydispersity of neat $\mathrm{HBPEAc-COOH}$ in tetrahydrofuran (THF) solution were measured by GPC (Model 1515, Waters) using polystyrene standard. The number average molecular weight and polydispersity were found to be $M_{n}=6,800$ and $M_{w} / M_{n}=1.42$, 
respectively. The advantage of the above HB polyester is in its photocuring capability of the acrylate double bonds and the carboxylic acid functionality that affords ionic interactions with its Nafion counterpart. The detailed synthetic scheme of these HB polyesters may be found in a previous paper [10]. ACS grade methanol was purchased from Sigma-Aldrich and used without further purification for dissolving hyperbranched polyester and swelling the ionic domains of Nafion.

Weighed Nafion membranes were pre-swollen in methanol for $24 \mathrm{~h}$ and then immersed in the $\mathrm{HBPEAc-COOH} / \mathrm{methanol}$ solution for $48 \mathrm{~h}$ at room temperature. The curing agent (Irgacure 907) in an amount of $3 \mathrm{wt} \%$ with respect to HBPEAc-COOH was added to the above solutions. The Nafion to HBPEAc-COOH polyester mass ratios were 98/2, 97/3, 95/5, 90/10 and 80/20. These ratios correspond to the feed compositions, which will be hereafter referred to as 'feed ratio'. Impregnated membranes were then removed from the HBPEAc-COOH/methanol solution and were gently blotted with tissue paper (e.g., Kimwipes) to remove excess methanol solution on the surface. Subsequently, the impregnated membranes were photocured in a curing chamber (NuLine, model NL22-8C, $\left.90 \mathrm{~mW} / \mathrm{cm}^{2}\right)$ at $\sim 85{ }^{\circ} \mathrm{C}$ for $5 \mathrm{~min}$, which is slightly above the glass transition temperature $\left(\mathrm{T}_{\mathrm{g}}\right)$ of the $\mathrm{HB}$ polyester. Blotting and curing procedures were conducted in a dark room so as to prevent accidental curing of the membranes. The HBPEAc-COOH impregnated Nafion membranes will be hereafter referred to as 'impregnated membranes'. These impregnated membranes were kept in a dessicator prior to use.

\subsection{Methods}

Thermal analyses of neat HBPEAc-COOH before and after photocuring were performed using a differential scanning calorimeter (DSC) using a modulated DSC 2920 (TA Instruments). The recommended amount of 7-10 $\mathrm{mg}$ of each sample was encapsulated in aluminum hermatic pans. DSC heating and cooling scans were carried out from 30 to $120^{\circ} \mathrm{C}$ at a rate of $10{ }^{\circ} \mathrm{C} \mathrm{min}^{-1}$ unless indicated otherwise. The DSC chamber was purged with nitrogen gas at a rate of $80 \mathrm{~mL} \mathrm{~min}^{-1}$.

${ }^{1} \mathrm{H}-{ }^{13} \mathrm{C}$ and ${ }^{19} \mathrm{~F}-{ }^{13} \mathrm{C}$ cross polarization (CP) and ${ }^{1} \mathrm{H}$ direct polarization (DP) magic angle spinning (MAS) solid-state nuclear magnetic resonance (SSNMR) spectra were collected on a Varian (Model: NMRS 500, $11.7 \mathrm{~T}$ ) spectrometer operated at $125.62 \mathrm{MHz}$ for ${ }^{13} \mathrm{C}$ and using a Varian narrow-bore triple-resonance T3 MAS NMR probe. Samples were packed into $4 \mathrm{~mm}$ zirconia rotors and spun at $10 \mathrm{kHz}$. The ${ }^{13} \mathrm{C}$ and ${ }^{1} \mathrm{H}$ chemical shifts were referenced to hexamethylbenzene (17.3 ppm; methyl) and adamantane (1.76 ppm). The ${ }^{1} \mathrm{H}_{-}{ }^{13} \mathrm{C}$ and ${ }^{19} \mathrm{~F}-{ }^{13} \mathrm{C}$ CP/MAS data were collected under continuous wave $(\mathrm{CW})$ proton and TPPM fluorine decoupling, respectively. A $90^{\circ}$ pulse width of $4 \mu$ s was used for all nuclei. Recycle delays of $2,2.5$ and $1 \mathrm{~s}$ were used for ${ }^{1} \mathrm{H}_{-}{ }^{13} \mathrm{C} \mathrm{CP},{ }^{19} \mathrm{~F}-{ }^{13} \mathrm{C} \mathrm{CP}$ and ${ }^{1} \mathrm{H} \mathrm{DP}$ experiments with contact times of 3.5 and $1.5 \mathrm{~ms}$ for the ${ }^{1} \mathrm{H}_{-}{ }^{13} \mathrm{C}$ and ${ }^{19} \mathrm{~F}-{ }^{13} \mathrm{C} \mathrm{CP}$ experiments. For the ${ }^{1} \mathrm{H}$ spectra, 32 transients were collected. Samples of neat Nafion-acid and impregnated membrane were stored in a dessicator and only exposed to ambient atmosphere while loading. The membranes were cut into a rectangular shape and rolled to fit into the rotors.

Fourier transform infrared (FTIR) spectra were collected in the attenuated total reflected mode (ATR) on a Nicolet 380 (Thermo Scientific) spectrometer with an average of 32 scans and a spectral resolution of $4 \mathrm{~cm}^{-1}$ at $\sim 100{ }^{\circ} \mathrm{C}$. Prior to the spectra collection, the membrane samples were equilibrated at $100{ }^{\circ} \mathrm{C}$ for about $10 \mathrm{~min}$ to eliminate possible moisture absorption. 
Quantification of the estimated amount of HBPEAc-COOH in the impregnated membranes was done by integrating the area under the FTIR curves within the wavenumber ranges of $1,670-1,770 \mathrm{~cm}^{-1}$ and 1,550-1,450 $\mathrm{cm}^{-1}$, which correspond to the carbonyl group and $\mathrm{C}=\mathrm{C}$ aromatic stretching peaks, respectively. The area under the FTIR absorption peak was normalized by that of pure HB polyester. The estimated amount of HB polyester was calculated by multiplying the percentage of $\mathrm{HBPEAc-COOH}$ present in membrane with the initial amount in feed and can be calculated using Equations (1) and (2) as described below;

$$
\begin{gathered}
\% \text { HBPEAc }-\mathrm{COOH}, \mathrm{x} \%=\frac{\mathrm{A}_{\text {Impregnated Membrane }}}{\mathrm{A}_{\mathrm{HBPEAc}-\mathrm{COOH}}} \times 100 \\
\text { Estimated weight of HBPEAc }-\mathrm{COOH}=\mathrm{x} \% \times \text { initial amount in feed }
\end{gathered}
$$

where $\mathrm{A}_{\text {Impregnated Membrane }}$ is the area under the curve from carbonyl and/or $\mathrm{C}=\mathrm{C}$ aromatic peak of each HBPEAc-COOH impregnated Nafion membrane and $\mathrm{A}_{\mathrm{HBPEAc}-\mathrm{COOH}}$ is the area under the curve from the $\mathrm{C}=\mathrm{O}$ and/or $\mathrm{C}=\mathrm{C}$ aromatic peaks of pure $\mathrm{HBPEAc}-\mathrm{COOH}$. Physical weighing measurements were carried out in order to cross-check the quantified amount of incorporated HBPEAc-COOH in Nafion membranes relative to those obtained from the integrated area under the FTIR spectral peaks.

Prior to the water uptake measurements, neat Nafion and HBPEAc-COOH impregnated Nafion membranes were dried in a vacuum oven until a constant weight was reached, which was taken as the mass in the dry state. All membranes were immersed in $10 \mathrm{~mL}$ deionized water at room temperature and equilibrated for $72 \mathrm{~h}$ for water uptake measurements. Membranes were then removed and blotted with dry tissue papers (Kimwipes) and the mass in wet state was recorded. Water uptake in percentage and the number of water molecules per mole of sulfonic group, $\lambda$, can be determined using Equations (3) and (4) as follows;

$$
\begin{gathered}
\text { Water Uptake }(\%)=\frac{\mathrm{M}_{\text {wet }}-\mathrm{M}_{\text {dry }}}{\mathrm{M}_{\mathrm{dry}}} \times 100 \% \\
\lambda\left(\operatorname{moles} \frac{\mathrm{H}_{2} \mathrm{O}}{\mathrm{SO}_{3}{ }^{-}}\right)=\frac{\left(\mathrm{M}_{\text {wet }}-\mathrm{M}_{\mathrm{dry}}\right) \times \mathrm{M}_{\text {eq Nafion } 115}}{\mathrm{M}_{\mathrm{dry}} \times \mathrm{M}_{\mathrm{H}_{2} \mathrm{O}}}
\end{gathered}
$$

where $M_{\text {wet }}$ is mass of the membrane in wet state, $M_{d r y}$ is mass of the membrane in dry state, $\mathrm{M}_{\text {eq Nafion } 115}$ is the equivalent weight of Nafion 115 and $\mathrm{M}_{\mathrm{H}_{2} \mathrm{O}}$ is the molecular mass of water.

Ion exchange capacity (IEC) of impregnated membranes and neat Nafion were conducted using titration method where weighed membrane samples were soaked in sodium chloride $(\mathrm{NaCl})$ solution for approximately $120 \mathrm{~h}$ to ensure complete conversion of proton to sodium cations. Solutions were then titrated with standardized $0.01 \mathrm{~N}$ sodium hydroxide $(\mathrm{NaOH})$ using a phenolphthalein indicator to the end point. IEC values in meq $\mathrm{g}^{-1}$ were calculated using the volume of sodium hydroxide $(\mathrm{NaOH})$ used to neutralize the solution with equation below;

$$
\text { Ion Exchange Capacity (IEC), meq g }{ }^{-1}=\frac{\mathrm{V}_{\text {titrated }} \times \mathrm{N}_{\mathrm{NaOH}}}{\mathrm{m}_{\text {membrane }}}
$$

where $V_{\text {titrated }}$ is the volume $(\mathrm{mL})$ of $\mathrm{NaOH}$ titrated to neutralize the solution, $\mathrm{N}_{\mathrm{NaOH}}$ is the standardized normality of $\mathrm{NaOH}$ and $\mathrm{m}_{\text {membrane }}$ is the mass (gram) of impregnated membranes or 
neat Nafion. Titration of each membrane samples were repeated five times and the mean of IEC values were reported.

Dynamic mechanical analyses (DMA) were measured in sinusoidal tension mode using a Pyris Diamond DMA (Perkin Elmer) equipped with a liquid nitrogen cooling controller (Seiko Equipment). Dried neat Nafion and impregnated membranes were cooled down to $-140{ }^{\circ} \mathrm{C}$ and maintained isothermally for $5 \mathrm{~min}$, then heated up to $200^{\circ} \mathrm{C}$ at a heating rate of $1{ }^{\circ} \mathrm{C} \mathrm{min}{ }^{-1}$. The frequency of the dynamic mechanical measurements was fixed at $1 \mathrm{~Hz}$ and measurements were carried out under the nitrogen environment.

Proton conductivity characterization of neat Nafion 115 and impregnated membranes were conducted using the AC impedance fuel cell device (Scribner, Model 850e Multi Range) equipped with adjustable reactant humidifier unit. Hydrogen $\left(\mathrm{H}_{2}\right)$ and compressed air were used as reactants with flow rate of $0.2 \mathrm{~L} \mathrm{~min}^{-1}$. Contact cell dimension used was $5 \mathrm{~cm}^{2}$ and membranes were tested at frequency range of $0.1 \mathrm{~Hz}-10 \mathrm{kHz}$. Measurements were conducted at two different relative humidity (RH) levels, i.e., $100 \% \mathrm{RH}$ and $74 \% \mathrm{RH}$ ranging from 30 to $110{ }^{\circ} \mathrm{C}$. Complex impedance data obtained were analyzed using the ZView program. Conductivity value can be calculated as follows;

$$
\text { Conductivity, } \sigma\left(\mathrm{S} \mathrm{cm}^{-1}\right)=\frac{\mathrm{d}}{\mathrm{R}_{\mathrm{p}} \mathrm{A}}
$$

where $d$ is thickness of the membrane $(\mathrm{cm}), R_{p}$ is the cell resistance $(\Omega)$ obtained from the intersection of the Nyquist plot and the real $\mathrm{Z}$ axis while $\mathrm{A}$ is the contact cell area $\left(\mathrm{cm}^{2}\right)$. Prior to the conductivity measurement, a spray gun (Badger Gun, Model No. 150) was used to coat the membranes with platinum supported carbon solution catalyst. Sprayed membranes with total weight catalyst of $2 \mathrm{mg}$ and $1 \mathrm{mg}$ on the cathode and anode side respectively were then manually compressed with $13.8 \mathrm{MPa}$ at $60{ }^{\circ} \mathrm{C}$ for $20 \mathrm{~s}$.

\section{Conclusions}

We have successfully incorporated large polymer molecules into the Nafion ionic domains via impregnation of hyperbranched supramolecules and subsequent photo-crosslinking in-situ. The FTIR studies suggested the occurrence of complexation, presumably inter-species hydrogen bonding between the carboxylic group of HB supramolecules and the sulfonate group of Nafion through bound water molecules. HBPEAc-COOH impregnated Nafion membranes exhibited lower swelling with improved dimensional stability in the presence of polar solvents. It was found that impregnating Nafion with HB solution increases the IEC values and therefore the proton density within the ionic clusters increases. The enhancement of IEC values in impregnated membranes can be attributed to the presence of collective protons from carboxylates in HB together with the primary protons of sulfonate groups in Nafion. Another important finding is the improved thermal stability of HBPEAc-COOH impregnated Nafion, showing the movement of the mechanical $\alpha$-relaxation to a higher temperature of $130{ }^{\circ} \mathrm{C}$ relative to $100{ }^{\circ} \mathrm{C}$ of the neat Nafion as well as the increase in the storage modulus. It may concluded that the impregnated membrane reveals an increasing trend of proton conductivity with temperature as opposed to the neat Nafion that shows the declining trend at elevated temperatures. Moreover, the present AC measurements on the impregnated membranes show no sign of deterioration in performance under the true proton fuel cell operating conditions in the repeated cycles up to $100{ }^{\circ} \mathrm{C}$, 
implying the durability of these impregnated membranes. Further, FTIR spectra of the HB impregnated membrane shows virtually unchanged before and after the cyclic AC impedance tests, which eliminates some doubts by others on possible hydrolysis of the HB polyesters at least for the duration (i.e., $160 \mathrm{~h}$ ) of the $\mathrm{AC}$ cyclic tests at $100{ }^{\circ} \mathrm{C}$ under the actual proton fuel cell conditions.

\section{Acknowledgments}

The authors are indebted to Robert Weiss and his group members, Emmanuel Pitia and Nathinee Srinate, for their invaluable suggestions and assistance in the operation of the AC impedance proton fuel cell device.

\section{References}

1 Grot, W.G.F. Discovery and development of Nafion perfluorinated membranes. Chem. Ind. 1985, 9, 647-649.

2 Grot, W.G.F. Perfluorinated ion exchange polymers and their use in research and industry. Macromol. Symp. 1994, 82, 161-172.

3 Barbir, F. PEM Fuel Cells: Theory and Practice; Elsevier Academic Press: Burlington, MA, USA, 2005.

4 Miyake, N.; Wainright, J.S.; Savinell, R.F. Evaluation of a sol-gel derived nafion/silica hybrid membrane for proton electrolyte membrane fuel cell applications: I. Proton conductivity and water content. J. Electrochem. Soc. 2001, 148, A898-A904.

5 DeLuca, N.W.; Elabd, Y.A. Nafion ${ }^{\circledR} /$ poly(vinyl alcohol) blends: Effect of composition and annealing temperature on transport properties. J. Membr. Sci. 2006, 282, 217-224.

6 Doyle, M.; Choi, S.K.; Proulx, G. High-temperature proton conducting membranes based on perfluorinated ionomer membrane-ionic liquid composites. J. Electrochem. Soc. 2000, 147, 34-37.

7 Schmidt, C.; Glück, T.; Schmidt-Naake, G. Modification of nafion membranes by impregnation with ionic liquids. Chem. Eng. Technol. 2008, 31, 13-22.

8 Mistry, M.K.; Subianto, S.; Choudhury, N.R.; Dutta, N.K. Interfacial interactions in aprotic ionic liquid based protonic membrane and its correlation with high temperature conductivity and thermal properties. Langmuir 2009, 25, 9240-9251.

9 Kannan, A.G.; Choudhury, N.R.; Dutta, N.K. In situ modification of Nafion ${ }^{\circledR}$ membranes with phospho-silicate for improved water retention and proton conduction. J. Membr. Sci. 2009, 333, 50-58.

10 Maruyama, K.; Kudo, H.; Ikehara, T.; Ito, N.; Nishikubo, T. Synthesis of photocrosslinkable hyperbranched polyesters and their film properties. J. Polym. Sci. Part A: Polym. Chem. 2005, 43, 4642-4653.

11 Zawodzinski, T.A.; Springer, T.E.; Davey, J.; Jestel, R.; Lopez, C.; Valerio, J.; Gottesfeld, S. Water uptake by and transport through Nafion ${ }^{\circledR} 117$ membranes. J. Electrochem. Soc. 1993, 140, 1981-1985.

12. Liu, S.-F.; Schmidt-Rohr, K. High-resolution solid-state ${ }^{13} \mathrm{C}$ NMR of fluoropolymers. Macromolecules 2001, 34, 8416-8418. 
13. Chen, Q.; Schmidt-Rohr, K. ${ }^{19} \mathrm{~F}$ and ${ }^{13} \mathrm{C}$ NMR signal assignment and analysis in a perfluorinated ionomer (nafion) by two-dimensional solid-state NMR. Macromolecules 2004, 37, 5995-6003.

14. Takasaki, M.; Kimura, K.; Kawaguchi, K.; Abe, A.; Katagiri, G. Structural analysis of a perfluorosulfonate ionomer in solution by ${ }^{19} \mathrm{~F}$ and ${ }^{13} \mathrm{C}$ NMR. Macromolecules 2005, 38, 6031-6037.

15. Bunce, N.J.; Sondheimer, S.J.; Fyfe, C.A. Proton NMR method for the quantitative determination of the water content of the polymeric fluorosulfonic acid Nafion-H. Macromolecules 1986, 19, 333-339.

16. Batamack, P.; Fraissard, J. Interaction of the perfluorinated polymer Nafion-H with water studied by proton broad-line NMR at $4 \mathrm{~K}$ and MAS NMR at room temperature. Catal. Lett. 1995, 35, 135-142.

17. Silverstein, R.M.; Webster, F.X.; Kiemle, D.J. Spectrometric Identification of Organic Compounds, 7th ed.; Wolfman-Robichaud, S., Ed.; John Wiley \& Sons Inc.: Hoboken, NJ, USA, 2005; Chapter 2, pp. 72-126.

18. Ostrowska, J.; Narębska, A. Infrared study of hydration and association of functional groups in a perfluorinated Nafion membrane, Part 1. Colloid Polym. Sci. 1983, 261, 93-98.

19. Falk, M. Perfluorinated Ionomer Membranes; Eisenberg, A., Yeager, H.L., Eds.; ACS Symp. Ser. 180; American Chemical Society: Washington, DC, USA, 1982; Chapter 8, pp. 139-171.

20. Yeo, R.S. Swelling studies of perfluorinated ionomer membranes. J. Appl. Polym. Sci. 1986, 32, 5733-5741.

21. Elliott, J.A.; Hanna, S.; Elliott, A.M.S.; Cooley, G.E. The swelling behaviour of perfluorinated ionomer membranes in ethanol/water mixtures. Polymer 2001, 42, 2251-2253.

22. Hinatsu, J.T.; Mizuhata, M.; Takenaka, H. Water uptake of perfluorosulfonic acid membranes from liquid water and water vapor. J. Electrochem. Soc. 1994, 141, 1493-1498.

23. Paddison, S.J. Proton conduction mechanisms at low degrees of hydration in sulfonic acid-based polymer electrolyte membranes. Annu. Rev. Mater. Res. 2003, 33, 289-319.

24. Kyu, T.; Hashiyama, M.; Eisenberg, A. Dynamic mechanical studies of partially ionized and neutralized Nafion polymers. Can. J. Chem. 1983, 61, 680-687.

25. Kyu, T.; Eisenberg, A. Underwater stress relaxation studies of Nafion (perfluorosulfonate) ionomer membranes. J. Polym. Sci. Polym. Symp. 1984, 71, 203-219.

26. Yuan, X.Z.; Song, C.; Wang, H.; Zhang, J. Electrochemical Impedance Spectroscopy in PEM Fuel Cells; Springer: London, UK, 2010; pp. 39-93.

27. Anantaraman, A.V.; Gardner, C.L. Studies on ion-exchange membranes. Part 1. Effect of humidity on the conductivity of Nafion ${ }^{\circledR}$. J. Electroanal.Chem. 1996, 414, 115-120.

28. Endoh, E.; Terazono, S.; Widjaja, H.; Takimoto, Y. Degradation study of MEA for PEMFCs under low humidity conditions. Electrochem. Solid State Lett. 2004, 7, A209-A211.

(C) 2011 by the authors; licensee MDPI, Basel, Switzerland. This article is an open access article distributed under the terms and conditions of the Creative Commons Attribution license (http://creativecommons.org/licenses/by/3.0/). 